\title{
Septal myectomy for patients with hypertrophic cardiomyopathy: A new paradigm
}

\author{
Rick A. Nishimura, MD, ${ }^{a}$ and Hartzell V. Schaff, $\mathrm{MD}^{\mathrm{b}}$
}

\author{
From the ${ }^{a}$ Division of Cardiovascular Diseases, Mayo Clinic, Rochester, Minn; and the ${ }^{\mathrm{b}}$ Division of Cardiovas- \\ cular Surgery, Mayo Clinic, Rochester, Minn. \\ Disclosures: Authors have nothing to disclose with regard to commercial support. \\ Received for publication Sept 11, 2015; accepted for publication Sept 14, 2015; available ahead of print \\ Oct 16, 2015. \\ Address for reprints: Rick A. Nishimura, MD, Division of Cardiovascular Diseases, Mayo Clinic, 200 First St, \\ SW, Rochester, MN 55905 (E-mail: rnishimura@mayo.edu or scipubs@ mayo.edu). \\ J Thorac Cardiovasc Surg 2016;151:303-4 \\ $0022-5223 / \$ 36.00$ \\ Copyright (c) 2016 by The American Association for Thoracic Surgery \\ http://dx.doi.org/10.1016/j.jtcvs.2015.09.068
}

Hypertrophic cardiomyopathy is a relatively common disease of the heart muscle, with an incidence of at least 1 in 500 of the United States population. The etiology is related to gene mutations of the sarcomere, resulting in hypertrophy of the myocardium. More than two-thirds of all patients with hypertrophic cardiomyopathy will have a unique dynamic left ventricular outflow tract obstruction as a result of septal hypertrophy, which protects into the left ventricular outflow tract, as well as abnormalities of the mitral valve apparatus, resulting in systolic anterior motion of the mitral valve. ${ }^{1}$ This causes obstruction to outflow with secondary mitral regurgitation, resulting in symptoms of exertional dyspnea, angina, and near syncope. Many patients can be treated medically with negative inotropic agents, but a subset of patients will have significant limiting symptoms despite optimal medical therapy. These symptoms can then be treated with septal reduction therapies, consisting of septal myectomy or septal ablation. Cardiac-related mortality in patients with hypertrophic cardiomyopathy occurs as a result of (1) progressive heart failure (usually associated with the dilated phase of the cardiomyopathy), (2) consequences of atrial fibrillation (including stroke and other embolic events), or (3) sudden cardiac death. Sudden cardiac death is primarily related to a primary electrical abnormality, with a substrate from interstitial fibrosis and scarring associated with the myocardial hypertrophy.

For patients with left ventricular outflow tract obstruction, transaortic septal myectomy is currently considered to be the criterion standard of septal reduction therapies. ${ }^{2,3}$ Careful resection of the basal septal hypertrophy with extension to the midventricular level can eliminate both outflow tract obstruction and the secondary mitral valve regurgitation. Symptom relief is excellent, with most patients returning back to a completely normal lifestyle. With improvements in operative technique, the risk associated with an isolated septal myectomy is now less than $1 \%$ at experienced surgical centers, with only rare complications of heart block, ventricular septal defect, and aortic valve regurgitation. The indication for septal

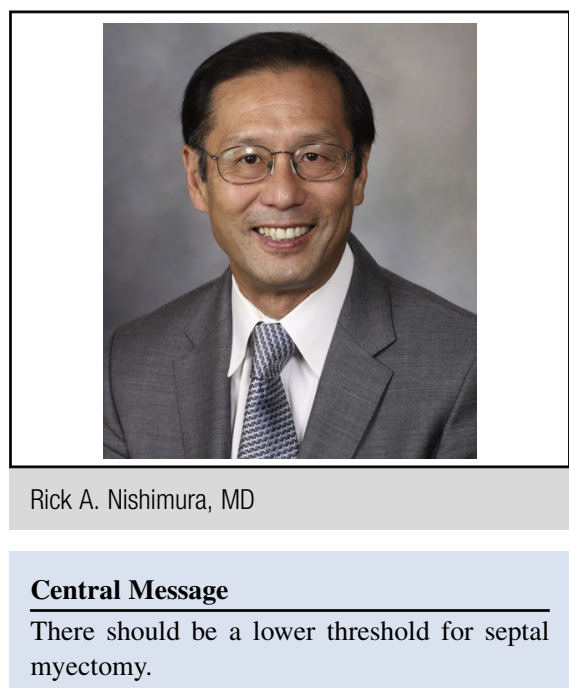

See Article page 928 in the October issue.

See Editorial Commentary page 936 in the October issue.

myectomy has been severe class III to IV heart failure symptoms unresponsive to medical therapy.

With the increasing success rate of septal myectomy combined with the very low operative mortality, centers with extensive experience in surgical treatment of hypertrophic obstructive cardiomyopathy have been lowering the threshold to proceed with operation. In contrast to valve replacement for aortic stenosis, septal myectomy results in a long-lasting durable relief of obstruction without creating another disease with potential complicationsthat is, insertion of a valve prosthesis. In our own practice, septal myectomy is also considered for patients who have only class II symptoms but are dissatisfied with limitations on their lifestyle, for patients who are having side effects from the medications that are controlling their symptoms, and for patients with symptoms with low resting gradients but provocable obstruction. ${ }^{4}$ In the October 2015 issue of the Journal, Desai and colleagues ${ }^{5}$ also propose septal myectomy for patients who do not report severe symptoms but demonstrate objective limitation on treadmill testing.

The effect of relieving outflow tract obstruction on survival of patients with hypertrophic cardiomyopathy is unclear, and for most patients anticipated reduction in 
cardiac death is not an indication for septal myectomy. It has been well documented in a number of studies, however, that patients with a left ventricular outflow tract obstruction, have an increased cardiac mortality relative to patients without outflow tract obstruction. ${ }^{6}$ In the study by Desai and colleagues, ${ }^{5}$ patients who underwent septal myectomy were compared with patients whose cases were managed with medical therapy alone. A composite end point of sudden death or implantable cardioverter-defibrillator discharge was significantly reduced in those patients who underwent the septal myectomy. This information supports findings of previous studies, which also compared patients who underwent septal myectomy with those whose cases were managed medically. In the study by Ommen and associates, ${ }^{7}$ overall mortality, hypertrophic cardiomyopathy-related mortality, and sudden cardiac death were significantly lower in the patients who had undergone myectomy than in those who were treated medically. The study by Ball and coworkers ${ }^{8}$ showed a significant improvement in overall survival in patients who underwent myectomy relative to those whose cases were managed medically. In addition, it was found that among patients who underwent implantable cardioverter-defibrillator implantation for primary prevention, the discharge rate of the defibrillator was markedly reduced after septal myectomy with respect both to patients who had not undergone myectomy and patients who had undergone septal ablation. ${ }^{9}$ Thus there is growing evidence that septal myectomy may indeed improve cardiac and overall mortality, as well as improving symptoms, in these patients with severe obstruction.

It is unclear why relief of outflow tract obstruction would improve mortality. Severe obstruction could certainly decrease coronary flow, however, resulting in a transient decrease in myocardial perfusion. The increase in left ventricular wall stress could promote endocardial ischemia. All could trigger malignant ventricular arrhythmias in patients who have underlying substrate for electrical events. In addition, long-standing pressure overload could lead to deleterious additional myocardial hypertrophy and fibrosis on top of the genetically present abnormal myocardium, which could then enhance the substrate for arrhythmias. It is not expected that any type of surgical procedure will be able to totally prevent sudden cardiac death. Relief of obstruction may be able to decrease the incidence of sudden death significantly, however, particularly in the younger population who are at increased risk.

One point in the study that should be noted is that this series of patients accounts for only two-thirds of patients who underwent septal myectomy during the interval of study. Among the 660 patients who were excluded, most were considered to have hypertensive heart disease as the cause of left ventricular outflow tract obstruction. In our experience, septal myectomy for left ventricular outflow tract obstruction in these elderly patients may be just as effective as it is for the younger cohort of patients who have genetically determined hypertrophic cardiomyopathy. The important issue for surgeons is that risk of operation in elderly patients is greater because of fragility of tissues and attendant comorbid conditions that contribute to surgical mortality and morbidity. In addition, conclusions regarding indications for operation that are based on the low risk of surgery in the subset of patients reported on here may not apply to all patients with outflow tract obstruction related to septal hypertrophy.

These data are based on a retrospective comparison of cohorts of patients, which will always have limitations as a result of selection bias. Because of the large number of patients necessary to treat, there will never be a randomized trial that can prove or disprove the hypothesis that relief of obstruction by septal myectomy will definitively prevent sudden cardiac death and improve survival. ${ }^{10}$ As we gain more knowledge from studies such as that of Desai and colleagues $^{5}$ regarding the overall long-term outcome of septal myectomy, however, we should consider the implications of continuing to lower the threshold for this very successful procedure.

\section{References}

1. Maron MS, Olivotto I, Zenovich AG, Link MS, Pandian NG, Kuvin JT, et al. Hypertrophic cardiomyopathy is predominantly a disease of left ventricular outflow tract obstruction. Circulation. 2006;114:2232-9.

2. Maron BJ, Nishimura RA. Surgical septal myectomy versus alcohol septal ablation: assessing the status of the controversy in 2014. Circulation. 2014;130: 1617-24.

3. American College of Cardiology Foundation/American Heart Association Task Force on Practice; American Association for Thoracic Surgery; American Society of Echocardiography; American Society of Nuclear Cardiology; Heart Failure Society of America; Heart Rhythm Society; Society for Cardiovascular Angiography and Interventions; Society of Thoracic Surgeons, , Gersh BJ, Maron BJ, Bonow RO, Dearani JA, Fifer MA, Link MS, et al. Guidelines. 2011 ACCF/AHA guideline for the diagnosis and treatment of hypertrophic cardiomyopathy: a report of the American College of Cardiology Foundation/American Heart Association Task Force on Practice Guidelines. J Thorac Cardiovasc Surg. 2011;142:e153-203.

4. Schaff HV, Dearani JA, Ommen SR, Sorajja P, Nishimura RA. Expanding the indications for septal myectomy in patients with hypertrophic cardiomyopathy: results of operation in patients with latent obstruction. J Thorac Cardiovasc Surg. 2012;143:303-9.

5. Desai MY, Smedira NG, Bhonsale A, Thamilarasan M, Lytle BW, Lever HM. Symptom assessment and exercise impairment in surgical decision making in hypertrophic obstructive cardiomyopathy: relationship to outcomes. J Thorac Cardiovasc Surg. 2015;150:928-35.e1.

6. Maron MS, Olivotto I, Betocchi S, Casey SA, Lesser JR, Losi MA, et al. Effect of left ventricular outflow tract obstruction on clinical outcome in hypertrophic cardiomyopathy. N Engl J Med. 2003;348:295-303.

7. Ommen SR, Maron BJ, Olivotto I, Maron MS, Cecchi F, Betocchi S, et al. Longterm effects of surgical septal myectomy on survival in patients with obstructive hypertrophic cardiomyopathy. J Am Coll Cardiol. 2005;46:470-6.

8. Ball W, Ivanov J, Rakowski H, Wigle ED, Linghorne M, Ralph-Edwards A, et al. Long-term survival in patients with resting obstructive hypertrophic cardiomyopathy: comparison of conservative versus invasive treatment. J Am Coll Cardiol. 2011;58:2313-21.

9. McLeod CJ, Ommen SR, Ackerman MJ, Weivoda PL, Shen WK, Dearani JA, et al. Surgical septal myectomy decreases the risk for appropriate implantable cardioverter defibrillator discharge in obstructive hypertrophic cardiomyopathy. Eur Heart J. 2007;28:2583-8.

10. Olivotto I, Ommen SR, Maron MS, Cecchi F, Maron BJ. Surgical myectomy versus alcohol septal ablation for obstructive hypertrophic cardiomyopathy: will there ever be a randomized trial? J Am Coll Cardiol. 2007;50:831-4. 